\title{
ACTIVATED COMBUSTION OF BIOMASS BLENDS BY MICROWAVE PRE-TREATMENT OF STRAW
}

\author{
Linards Goldsteins, Raimonds Valdmanis, Maija Zake \\ Institute of Physics, University of Latvia, Latvia \\ linards.goldsteins@lu.lv, raimonds.valdmanis@lu.lv,maija.zake@lu.lv
}

\begin{abstract}
The aim of this study is to investigate the heat production and emissions of biomass blends consisting of commercial wood pellets and microwave (MW) pre-treated wheat straw pellets to intensify use of the straw in energy production. Three types of blends of wood and straw pellets with different pre-treatment conditions were used in this study. An experimental device consisting of a gasifier and combustor was used to analyse the effect of MW pre-treatment in blends on combustion characteristics: flame temperature, total heat power and product composition. The study revealed that MW pre-treatment of straw pellets enhances combustion characteristics of blends: faster thermal decomposition, increase of the flame temperature and combustion efficiency.
\end{abstract}

Keywords: lignocellulosic pellets, microwave activation, combustion characteristics, composition of emissions.

\section{Introduction}

Lignocellulosic biomass is an abundant renewable energy source, the use of which for energy production allows reducing greenhouse gas emissions [1]. Therefore, the gradual replacement of fossil fuels with different types of renewable fuels for energy production is considered as a promising tool to control global warming $[2 ; 3]$. To provide such replacement, combustion of different renewable solid fuels can be used in practical applications [4]. Combustion of biomass blends with wheat straw, which is a widespread biomass with a relatively high energy potential, is of high particular interest [5].

For an additional process control and improvement, if the low calorific value straw is combusted with wood or peat, the main characteristics of straw pellets can be improved providing microwave (MW) pre-treatment of pellets [6-8]. MW pre-treatment of pellets results in structural changes of pellets increasing their porosity and reactivity, which promotes faster and more complete combustion of pretreated pellets. In addition, MW pre-treatment causes the variations of the elemental and chemical composition of pellets increasing their heating values [9; 10].

Consequently, if MW pre-treated straw is combusted with other solid fuels, increased reactivity and heating value of straw pellets can be used to activate the thermo-chemical conversion of the solid fuel blends. The MW effect depends on pre-treatment conditions and the mass load of straw pellets in the blend. Therefore, the optimal MW pre-treatment regimes and optimal composition of these blends must be estimated to provide an effective control of their thermo-chemical conversion and composition of emissions. This allows minimizing the impact of the somewhat problematic fuel, such as wheat straw pellets, or even improving combustion characteristics of such widely used biomass fuel as wood and which is the main goal of the presented study.

\section{Materials and methods}

Two types of pilot-scale experimental devices were used to study the thermal decomposition and combustion of MW activated biomass blends.

First, a MW reactor was used for pre-treatment of wheat straw pellets using the two-stage process of biomass heating, which combines convective and MW heating of pellets in the Ar atmosphere [8]. To control structural changes of pellets due to MW pre-treatment, change of the weight, variations of the surface area and porosity were measured. The higher heating value (HHV) of pre-treated pellets was estimated from measurements of their elemental composition by varying the pre-treatment regime using the methods which are described in [4].

In this study two different regimes of pre-treatment temperatures of wheat straw were used $T_{m w}=473 \mathrm{~K}$ and $T_{m w}=548 \mathrm{~K}$.

Secondly, an experimental device with a heat power up to $5 \mathrm{~kW}$ consisting of a gasifier and a combustor [11] was used to study the combustion characteristics of blends of commercially available, untreated wood pellets with 3 types of wheat straw pellets: untreated and pre-treated at $T_{m w}=473 \mathrm{~K}$ and $T_{m w}=548 \mathrm{~K}$. The gasifier was filled with a constant volume and total mass 340-480 g of biomass blends. The thermal decomposition of blends was initiated using an additional heat supply by propane flame 
flow and was supported using the primary air supply below the layer of blend with average rate $0.8 \mathrm{~g} \cdot \mathrm{s}^{-1}$, thus enhancing the yield of volatiles $\left(\mathrm{CO}, \mathrm{H}_{2}, \mathrm{C}_{\mathrm{x}} \mathrm{H}_{\mathrm{y}}, \mathrm{CO}_{2}\right)$, The effect of MW pre-treatment was studied by varying the mass fraction of wheat straw in the blends from $15 \%$ to $60 \%$. The burnout of volatiles downstream of the combustor was enhanced using a secondary swirling air supply at the flame base with the average air supply rate $1.22 \mathrm{~g} \cdot \mathrm{s}^{-1}$, ensuring the formation of near-stoichiometric inlet conditions at the flame base ( $\alpha \approx 0.95-1.3)$. The effects of MW pre-treatment regime of the wheat straw pellets and the composition of the fuel blends on kinetics and average values of the flame temperature, heat capacity and composition of emissions were studied using the thermocouples, Testo 350 gas analyser and calorimetric measurements of cooling the water flow of the device. Measurement methods and the estimated accuracy are described in detail in [4].

\section{Results and discussion}

The experimental results of biomass blend combustion using MW pre-treated straw pellets show significant increase of the volume fraction of combustible volatiles (normalized to wood pellets) at the flame base (Fig. 1-a), which accordingly leads to decrease of the air excess ratio (Fig.1-b). Such results suggest that reactivity of MW pre-treated pellets has been increased and it enhances the thermal decomposition of the entire biomass blend. This result is supported by a faster burnout of the activated blends (Fig. 1-c), where duration of the thermochemical conversion of the activated blends can be decreased by about $20-35 \%$ compared to raw wood pellets.

It should be noted that kinetics and average values of the flame temperature during thermochemical conversion of the blends of pre-treated wheat straw with raw wood pellets is influenced by the development of the sequence of gas-phase and surface reactions (1-6). Increasing the pre-treatment temperature of wheat straw pellets enhances the development of gas-phase reactions $(1,2)$ responsible for intensive heat release and energy production [9], thus increasing the flame temperature (Fig. $1-\mathrm{c}$ ). Measurements of the carbon content in pretreated pellets show carbonization of wheat straw pellets during MW pre-treatment [11] increasing HHV of pre-treated pellets (Fig. 1-d). Carbonization of wheat straw pellets leads to gradual transition from the gas-phase combustion to development of surface reactions $(3,4)$. Thermochemical conversion of carbonized wheat straw pellets enhances the development of competitive endothermic surface reactions $(5,6)$ by varying the yield of $\mathrm{CO}_{2}$ (normalized to wood pellets) at the flame base (Fig. 1-e).

It suggests that gradual transition from gas-phase to surface reactions results in a decrease of the flame length and temperature of the flame reaction zone determining the formation of the shoulder-like temperature kinetics during the final stage of thermochemical conversion (Fig. 1-c).

$$
\begin{gathered}
\mathrm{H}_{2}+0.5 \mathrm{O}_{2} \rightarrow \mathrm{H}_{2} \mathrm{O} \Delta \mathrm{H}=-242 \mathrm{~kJ} \cdot \mathrm{mol}^{-1} \\
\mathrm{CO}+0.5 \mathrm{O}_{2} \rightarrow \mathrm{CO}_{2} \Delta \mathrm{H}=-283 \mathrm{~kJ} \cdot \mathrm{mol}^{-1} \\
\mathrm{C}+0.5 \mathrm{O}_{2} \rightarrow \mathrm{CO} \Delta \mathrm{H}=-123.1 \mathrm{~kJ} \cdot \mathrm{mol}^{-1} \\
\mathrm{C}+\mathrm{O}_{2} \rightarrow \mathrm{CO}_{2} \Delta \mathrm{H}=-393.5 \mathrm{~kJ} \cdot \mathrm{mol}^{-1} \\
\mathrm{C}+\mathrm{CO}_{2} \rightarrow 2 \mathrm{CO} \Delta \mathrm{H}=+159.9 \mathrm{~kJ} \cdot \mathrm{mol}^{-1} \\
\mathrm{C}+\mathrm{H}_{2} \mathrm{O} \leftrightarrow \mathrm{CO}+\mathrm{H}_{2} \Delta \mathrm{H}=+118.5 \mathrm{~kJ} \cdot \mathrm{mol}^{-1}
\end{gathered}
$$

From (Fig. 1-d) follows that HHV of blends depends on pre-treatment regime of wheat straw pellets and the mass fraction of pre-treated wheat straw in blends. The HHV of wheat straw pellets increases from $16.5 \mathrm{MJ} \cdot \mathrm{kg}^{-1}$ of untreated pellets to $18.5 \mathrm{MJ} \cdot \mathrm{kg}^{-1}$ at $\mathrm{MW}$ pre-treatment temperature $T_{m w}=473 \mathrm{~K}$ and to $20.5 \mathrm{MJ} \cdot \mathrm{kg}^{-1}$ at $T_{m w}=543 \mathrm{~K}$, which follows the tendency in [8], where wood pellets were pretreated. The HHV of raw wood pellets used in present study was ca. $18.5 \mathrm{MJ} \cdot \mathrm{kg}^{-1}$.

Estimations of HHV of the blends have shown that HHV of raw wheat straw and wood pellet blends decreases by increasing the mass fraction of untreated wheat straw pellets in the blends, with $T_{m w}=473 \mathrm{~K}$ pre-treated straw pellets is practically constant, while increases using $T_{m w}=543 \mathrm{~K}$ pretreated straw pellets. 

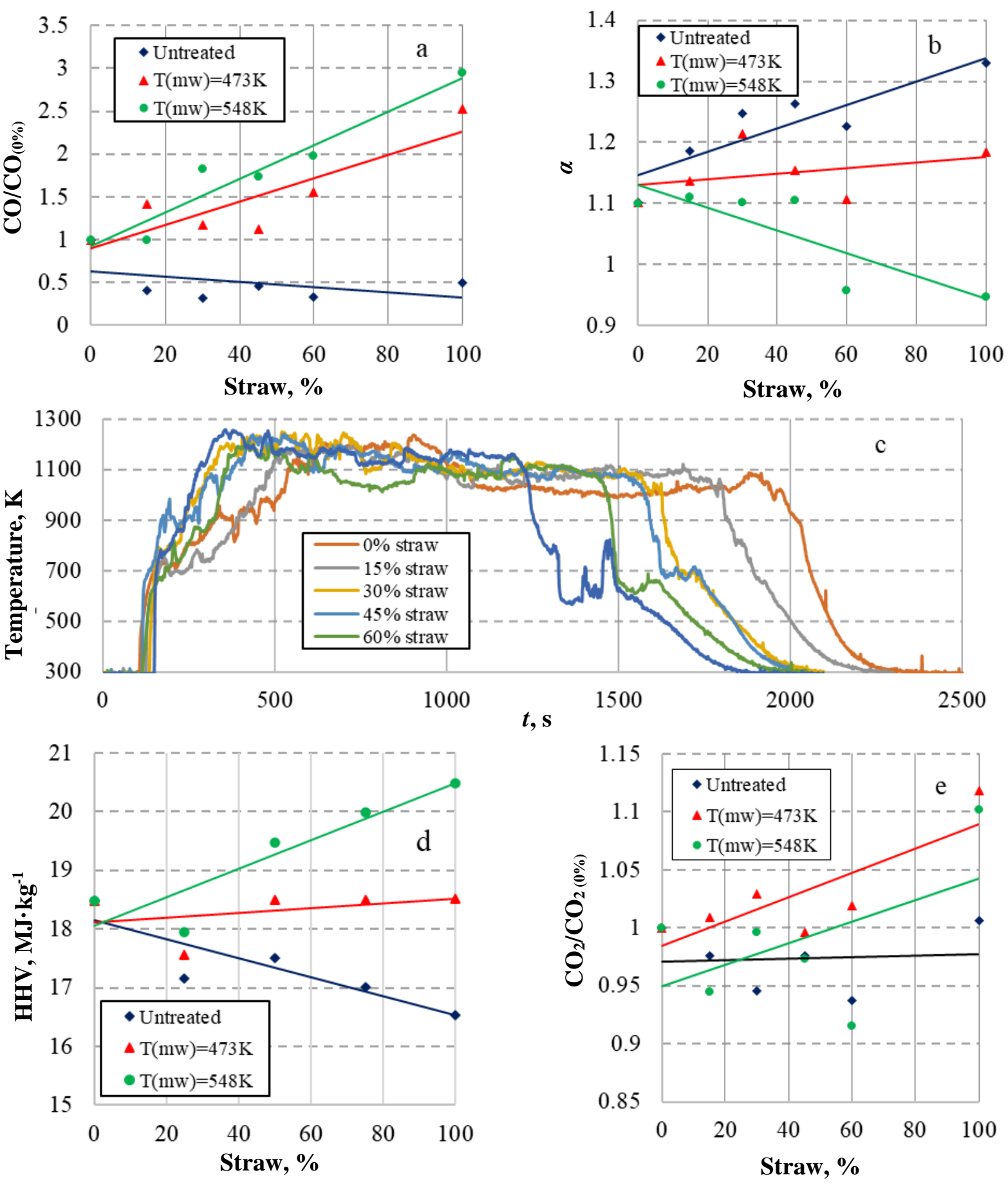

Fig. 1. Effect of variation of the wheat straw pre-treatment temperature and the mass fraction of pre-treated wheat straw pellets in the blend on: $a, b$ - normalized mass fraction of combustible volatiles $-\mathrm{CO}$ and the air excess ratio $-\alpha$ at the inlet of the combustor; $\mathrm{c}-$ kinetics of the flame temperature $T_{m w}=543 \mathrm{~K} ; \mathrm{d}-\mathrm{HHV}$ of the blend; $\mathrm{e}-$ normalized yield of $\mathrm{CO}_{2}$

Kinetics of produced heat using blends with $T_{m w}=543 \mathrm{~K}$ pre-treated straw pellets are shown in (Fig. 2 - a). It can be observed that increasing the mass fraction of pre-treated wheat straw pellets in blends enhances transition to self-sustaining combustion of volatiles. Produced heat power during the self-sustaining thermo-chemical conversion of blends approaches to $4.5-5 \mathrm{~kW}$. Average heat power (Fig. $2-$ b) is influenced by development of the sequence of the gas-phase and surface reactions (1-6) promoting a large dispersion of the results with a slight tendency to increase with the pre-treatment temperature of wheat straw pellets. Volume fraction of $\mathrm{CO}_{2}$ in emissions is shown in (Fig. $2-\mathrm{c}$ ) and it can be observed that levels of $\mathrm{CO}_{2}$ increase with MW pre-treatment temperature and straw content. 
Increase of $\mathrm{CO}_{2}$ in emissions indicates the increase of combustion efficiency, as shown in (Fig. $2-\mathrm{d}$ ). While measured increase in combustion efficiency is ca. 1\%, it has been shown that increase of the pretreatment temperature can have a positive effect on the combustion characteristics.


Fig. 2. Effect of variation of the wheat straw pre-treatment temperature and the mass fraction of pre-treated wheat straw pellets in the blend with raw wood pellets on: a - kinetics of the heat production; $\mathrm{b}$ - average values of the produced heat; $\mathrm{c}$ - volume fraction of $\mathrm{CO}_{2}$ emission in the products; $d$ - combustion efficiency

\section{Conclusions}

The experimental study has shown that the MW pre-treatment of wheat straw pellets results in variations of the thermochemical conversion of the biomass blends (pre-treated wheat straw and raw wood pellets), which depend on the pre-treatment temperature of wheat straw pellets and the mass fraction of pre-treated straw in the mixture. Increased reactivity and the HHV value of wheat straw pellets cause elevated yield of combustible volatiles at the flame base and improved combustion conditions. This leads to a faster transition to flaming combustion of volatiles increasing the temperature of the reaction zone and faster thermochemical conversion of blends and decreasing the duration of the mixture thermochemical conversion by about $20-35 \%$. The observed carbonization of wheat straw pellets during their pre-treatment promotes a gradual transition from the flaming combustion to surface reactions and formation of the shoulder in the temperature curve. The measured increase of $\mathrm{CO}_{2}$ in emissions and the corresponding combustion efficiency allow concluding that MW pre-treatment of wheat straw pellets can be used as a tool to provide effective control of the combustion characteristics of blends with beneficial use of straw as a fuel for energy production. 


\section{Acknowledgements}

The authors would like to acknowledge financial support from the European Regional funding of project No. 1.1.1.1/19/A/010.

\section{References}

[1] Hameed Z., Naqvi S. Z., Naqvi M., Ali I., Taqvi S.A.A., Gao N., Hussain S. A., and Hussain S. A. Comprehensive Review on Thermal Coconversion of Biomass, Sludge, Coal, and Their Blends Using Thermogravimetric Analysis. Journal of Chemistry, vol. 2020, 2020, pp. 1-23,

[2] Baxter L. Biomass-coal co-combustion: Opportunity for affordable renewable energy, Fuel, vol. 84, N10, 2005, pp. 1295-1302.

[3] Nussbaumer T. Combustion and co-combustion of biomass: fundamentals, technologies, and primary measures for pollutant reduction. Energy\&Fuels, vol. 17, 2003, pp. 1510-1521.

[4] Kolmickovs A., Barmina I., Valdmanis R., Zake M., Kalis H., Strautins U. Electric field effect on the thermal decomposition and co-combustion of straw pellets with solid fuel pellets. Energies vol. 12 (8), 2019, pp. 1 - 24.

[5] Olsson M. Wheat straw and peat for fuel pellets - organic compounds from combustion. Biomass and Bioenergy, vol. 30, 2011, pp. 555-564.

[6] Ethaib S. Omar R., Kamal S.M.M., Biak D.R.A. Microwave-assisted pretreatment of lignocellulosic biomass: a review. Journal of Engineering Science and Technology, vol. 10, 2015, pp. 97- 109.

[7] Ingole P.M., Ranveer A.C., Deshmukh S.M., Deshmukh S. K. Microwave assisted pyrolysis of biomass: a review. International Journal of advanced Technology in Engineering and Science, vol. 4 (6), 2016, pp. $78-84$.

[8] Arshanitsa A., Akishin Y., Zile E., Dizhbite T., Solodovnik V., Telysheva G. Microwave treatment combined with conventional heating of plant biomass pellets in a rotated reactor as a high rate process for solid biofuel manufacture. Renewable Energy, vol. 91, 2016, pp. 386-396.

[9] Yu-Fong H., Pei-Te C., Shang-Lien L. Review on microwave pyrolysis of lignocellulosic biomass. Sustainable Environment Research, vol. 26, 2016, pp. 103-109.

[10] Mitani T. Recent progress on microwave pre-processing of biomass for bioenergy production. Journal of Japan Petroleum Institute, vol. 61 (2), pp. 113-120.

[11] Goldsteins L., Valdmanis R., Zake M., Arshanitsa A., Andersone A. Thermal Decomposition and Combustion of Microwave Pre-treated Biomass Pellets. Processes 2021, 9, 492. DOI: $10.3390 /$ pr9030492 